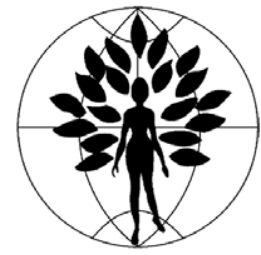

www.figo.org

\title{
Twin weight discordance and maternal weight gain in twin pregnancies
}

\author{
K.J. Lee ${ }^{a, *}$, J. Hur ${ }^{b}$, J. Yoo ${ }^{c}$ \\ ${ }^{a}$ Department of Obstetrics and Gynecology, Pochon CHA University College of Medicine, Seoul, Korea \\ ${ }^{\mathrm{b}}$ Bioinformatics Program, University of Michigan, Ann Arbor, MI, USA \\ c Cancer Metastasis Research Center, Yonsei University College of Medicine, Seoul, Korea
}

Received 16 August 2006; received in revised form 20 November 2006; accepted 20 November 2006

\section{KEYWORDS}

Twin weight discordance; Maternal Body Mass Index (BMI)

\begin{abstract}
Objective: To evaluate the association between twin weight discordance and maternal weight change during the gestational period. Method: One hundred forty-seven twin pregnancies (Group A: $<25 \%$, Group $B: \geq 25 \%$ birth weight discordance) were analyzed using Student's t-test, $\chi^{2}$-test, and two-way ANOVA at three gestational intervals: before 18 weeks, 18 to 28 weeks, and 28 weeks to birth. Result: There was no statistically significant difference between the two groups involving maternal age, parity, duration of pregnancy, height, pregravid weight, and conception method. Group A showed a pattern of constantly increasing maternal weight without a significant change in the twin weight discordance throughout gestation. However, Group B showed a fluctuation in maternal BMI with remarkably elevated twin weight discordance at 28 weeks to birth. Conclusion: The results suggest that in twin pregnancies constant maternal weight gain throughout gestation is important for maintaining a twin weight discordance of less than $25 \%$.

(c) 2007 International Federation of Gynecology and Obstetrics. Published by Elsevier Ireland Ltd. All rights reserved.
\end{abstract}

\section{Introduction}

Multiple births have increased substantially in recent years due to the increased use of assisted reproductive technology (ART) and the increased number of delayed pregnancies [1]. Although twin babies are usually more mature than singleton babies at the same gestational age, intrauterine growth

\footnotetext{
* Corresponding author. Tel.: +82 23468 3128; fax: +82 25581119.

E-mail addresses: drlkj52551@hanmail.net (K.J. Lee), juhur@umich.edu (J. Hur), jino12@freechal.com (J. Yoo).
}

restrictions and prematurity contribute to higher perinatal morbidity and mortality in twin births rather than singleton births [2-4]. High inter-twin weight discordance can have health consequences to the babies, especially to the smaller infant, which is influenced predominately by the uterine environment $[2,5]$. Proper and balanced fetal growth is the most important factor for an infant's health. Proper infant growth is heavily dependent upon maternal nutritional status [6-8].

Many studies have addressed the importance of appropriate nutritional ingestion by mothers. These studies have

0020-7292/\$ - see front matter @ 2007 International Federation of Gynecology and Obstetrics. Published by Elsevier Ireland Ltd. All rights reserved. 
Table 1 Characteristics in twin pregnancies

\begin{tabular}{|c|c|c|}
\hline \multirow[t]{2}{*}{ Characteristics } & \multirow{2}{*}{$\begin{array}{l}\text { Group A } \\
\text { Twin with }<25 \% \\
\text { discordance }\end{array}$} & \multirow{2}{*}{$\begin{array}{l}\text { Group B } \\
\text { Twin with } \geq 25 \% \\
\text { discordance }\end{array}$} \\
\hline & & \\
\hline Number of pregnancy & 109 & 38 \\
\hline Age & $33.09 \pm 0.34$ & $33.63 \pm 0.64$ \\
\hline Parity & $0.5 \pm 0.07$ & $0.34 \pm 0.12$ \\
\hline $\begin{array}{l}\text { Duration of pregnancy } \\
\text { (week) }\end{array}$ & $36.66 \pm 0.15$ & $36.42 \pm 0.30$ \\
\hline Pregravid weight (kg) & $55.34 \pm 0.85$ & $55.87 \pm 1.30$ \\
\hline Height (m) & $1.61 \pm 0.0$ & $1.61 \pm 0.00$ \\
\hline \multicolumn{3}{|l|}{ Pregnant status } \\
\hline Natural pregnancy & 19 & 3 \\
\hline Artificial pregnancy & 90 & 35 \\
\hline Race & Asian & Asian \\
\hline Smoking & No & No \\
\hline Alcohol & No & No \\
\hline $\begin{array}{l}\text { Maternal total weight } \\
\text { increase }(\mathrm{kg})\end{array}$ & $17.52 \pm 0.53$ & $13.02 \pm 1.04$ \\
\hline $\begin{array}{l}\text { Sum of fetal birth } \\
\text { weight }(\mathrm{g})\end{array}$ & $4972.3 \pm 69.36$ & $4634.7 \pm 111.12$ \\
\hline \multicolumn{3}{|l|}{$\begin{array}{l}\text { Maternal BMI changes } \\
\left(\mathrm{kg} / \mathrm{m}^{2}\right)\end{array}$} \\
\hline Interval-I & $0.53 \pm 0.10$ & $-2.01 \pm 1.32$ \\
\hline Interval-II & $2.97 \pm 0.11$ & $4.91 \pm 1.26$ \\
\hline Interval-III & $3.29 \pm 0.16$ & $2.16 \pm 0.64$ \\
\hline \multicolumn{3}{|l|}{$\begin{array}{l}\text { Twin weight } \\
\text { discordance (\%) }\end{array}$} \\
\hline Interval-I & $8.29 \pm 0.67$ & $11.54 \pm 1.25$ \\
\hline Interval-II & $7.79 \pm 0.55$ & $13.19 \pm 1.38$ \\
\hline Interval-III & $9.07 \pm 0.55$ & $32.92 \pm 1.16$ \\
\hline
\end{tabular}

also determined the gestational ages that have the most significant effect on twin birth weight [6,8-10]. In fact, maternal weight gain is closely related to intrauterine growth and birth weight [11-15]. Blickstein et al. [5,16] reported that fetal growth discordance would decrease along with sufficient maternal weight gain because this maternal weight gain provides an appropriate uterine environment to nurture both twins properly. These previous studies have focused on the association between twin birth weight discordance and maternal weight change over the entire gestational period.

In contrast, our study evaluates the relationship between maternal weight change and fetal weight discordance at different gestational intervals during twin pregnancy.

\section{Materials and methods}

\subsection{Study population}

The study population included all the twin births delivered at Kangnam CHA hospital with an in vitro fertilization center in Korea between February 2002 and May 2004. The study sample was limited to pregnancies that met the following inclusion criteria: (1) antenatal care by the Kangnam CHA hospital throughout the pregnancy, (2) both twins born alive (3) 5-minute APGAR scores no less than 7 at birth, (4) measurement of both maternal weight and fetal ultrasonographic weight at each hospital visit, (5) absence of major congenital anomalies as documented by normal findings in the newborn medical record, and (6) no hypertension nor gestational diabetes during pregnancy. The twin pregnancies meeting all the above criteria were divided into two subset populations depending on the degree of twin weight discordance at birth. The weight discordance was defined as the intra-pair difference expressed as the percentage of the heavier twin's weight. Group A included pairs with a $<25 \%$ discordance and Group $B$ included twins with $a \geq 25 \%$ discordance.

\subsection{Weight measurement}

Maternal and fetal weight data were collected for three gestational time intervals: Interval-I (before 18 weeks), Interval-II (between 18 and 28 weeks), and Interval-III (between 28 weeks and birth). Two expert obstetricians performed the ultrasonographies and estimated fetal weight by the Hadlock's formula using biparietal diameter, abdominal circumference, and femur length [17].

\subsection{Study variables}

The abstracted data included maternal age, parity, gestational age, maternal size variables (height, pregravid weight, and Body Mass Index (BMI: [weight / (height $\times$ height)]), race, smoking and drinking alcohol during pregnancy, chorionicity (dichorionic or monochorionic), maternal weight measurement, and fetal weight estimated by ultrasonography at each prenatal care visit, twin birth weight, and infant gender [10].
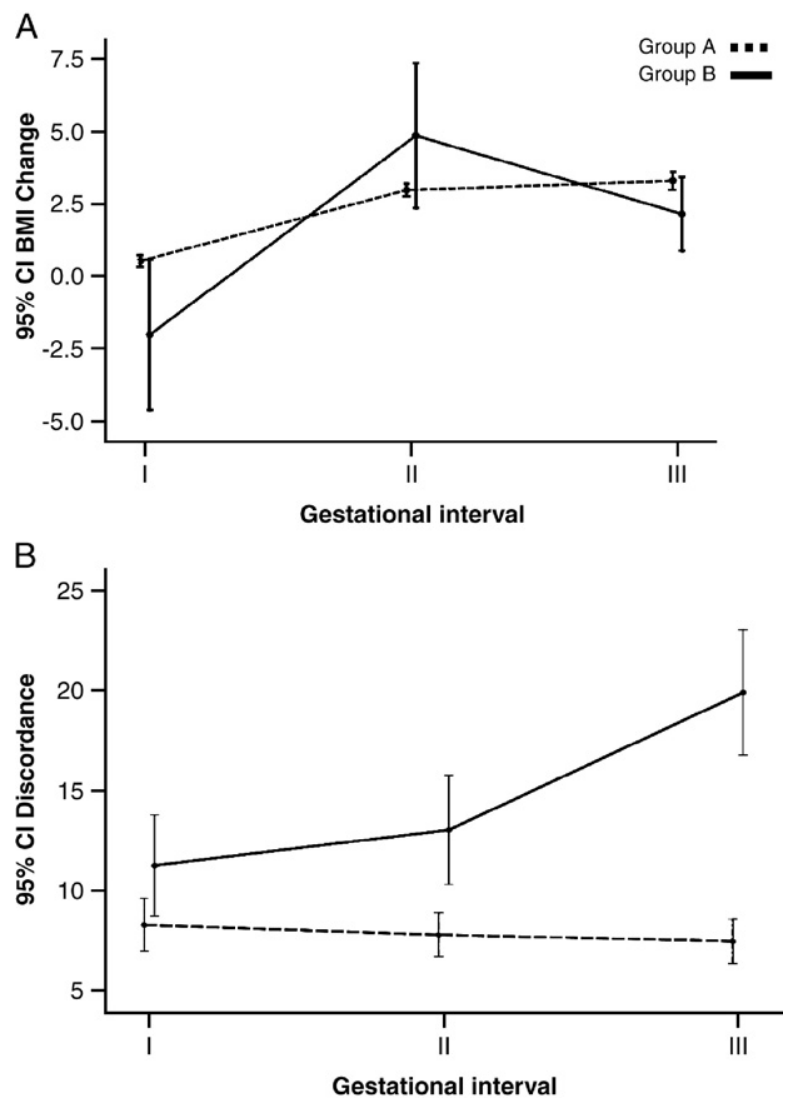

Figure 1 Patterns of maternal BMI and fetal weight changes over three gestational intervals. 


\subsection{Statistical analyses}

Descriptive statistics were used to evaluate the relationships among the variables described above. The rates of maternal weight gain and twin weight discordance were estimated from linear regression curves that were fitted to the measured weights at each gestational period. The Student's $t$-test and chisquare test were employed to identify significant differences among the variables. A two-way ANOVA was performed in order to test the difference in maternal BMI change and twin weight discordance at each gestational interval between Groups A and B. All tests were two-sided and the significance level was set at $\alpha=0.05$. The SPSS software package (Version 13 SPSS Inc, Chicago, Illinois, USA) was used for statistical analyses.

\section{Results}

One hundred forty-seven out of 251 twin pregnancies met our inclusion criteria. Based on birth weight discordance, 109 pregnancies were categorized as Group A and 38 pregnancies as Group B. Ultrasonographic fetal weight estimation proved to be a reliable measure by a comparison of the birth weight with the estimated fetal weight immediately prior to delivery (Pearson correlation coefficient $=0.748$, $p=0.000$ ).

Table 1 shows the maternal characteristics of the two groups. The mean gestational ages were 15.57 weeks at the first interval, 24.71 weeks at the second interval, and 36.57 weeks at the third interval. The study population was composed of a single race and did not include any cases with mothers who smoked or drank alcohol during pregnancy. We found no statistically significant differences between the two groups with regard to maternal age, parity, pregnancy duration, height, pregravid weight, or conception method.

Total maternal weight gain and the sum of the twins' fetal birth weights were significantly higher in Group A than in Group B $(17.52 \pm 0.53 \mathrm{~kg}$ and $4972.3 \pm 69.36 \mathrm{~g}$ for Group A versus $13.0 \pm 1.04 \mathrm{~kg}$ and $4633.0 \pm 111.12 \mathrm{~g}$ for Group $\mathrm{B}$, respectively, $p=0.005)$. Since body weight change can be dependent on individual height, Body Mass Index (BMI) was used in further analyses to counterbalance the effect of height variance.

The mean maternal BMI changes for Groups $A$ and $B$ at each interval were $0.53 \pm 0.10 \mathrm{~kg} / \mathrm{m}^{2}$ and $2.01 \pm 1.32 \mathrm{~kg} / \mathrm{m}^{2}$ before 18 weeks, $2.97 \pm 0.11 \mathrm{~kg} / \mathrm{m}^{2}$ and $4.91 \pm 1.26 \mathrm{~kg} / \mathrm{m}^{2}$ between 18 weeks and 28 weeks, and $3.29 \pm 0.16 \mathrm{~kg} / \mathrm{m}^{2}$ and $2.16 \pm$ $0.64 \mathrm{~kg} / \mathrm{m}^{2}$ between 28 weeks and birth. Fig. 1A shows the patterns of maternal BMI change during the gestational period in each group. Group A exhibits a constantly increasing pattern from Interval-I to Interval-II $(p=0.000)$ and from Interval-II to Interval-III $(p=0.230)$. However Group B shows a fluctuating pattern with a decrease during Interval-I, a significant gain from Interval-I to Interval-II $(p=0.000)$, and a slight decrease from Interval-II to Interval-III $(p=0.228)$. The patterns of twin weight discordance change during

Table 2 Maternal and fetal characteristics according to chorionicity and gender of discordant twins

\begin{tabular}{|c|c|c|c|c|c|}
\hline \multirow[t]{2}{*}{ Characteristics } & & \multicolumn{2}{|l|}{ Chorionicity } & \multicolumn{2}{|l|}{ Gender } \\
\hline & & Dichorionicity & Monochorionicity & With male & Both female \\
\hline \multirow[t]{2}{*}{ Number of pregnancy } & Group A & 94 & 15 & 77 & 32 \\
\hline & Group B & 36 & 2 & 29 & 9 \\
\hline \multirow[t]{2}{*}{ Age } & Group A & $33.79 \pm 0.35$ & $31.2 \pm 1.00$ & $33.14 \pm 0.38$ & $32.97 \pm 0.74^{*}$ \\
\hline & Group B & $33.78 \pm 0.66$ & $31.0 \pm 2.00$ & $32.79 \pm 0.61$ & $36.33 \pm 1.62$ \\
\hline \multirow[t]{2}{*}{ Parity } & Group A & $0.46 \pm 0.07$ & $0.8 \pm 0.24$ & $0.55 \pm 0.09$ & $0.41 \pm 0.13$ \\
\hline & Group B & $0.25 \pm 0.10$ & $2.0 \pm 1.0$ & $0.28 \pm 0.12$ & $0.56 \pm 0.34$ \\
\hline \multirow[t]{2}{*}{ Duration of pregnancy (week) } & Group A & $36.66 \pm 0.16$ & $36.64 \pm 0.33$ & $36.48 \pm 0.19$ & $37.08 \pm 0.20$ \\
\hline & Group B & $36.35 \pm 0.31$ & $37.50 \pm 0.50$ & $36.58 \pm 0.27$ & $35.91 \pm 0.96$ \\
\hline \multirow[t]{2}{*}{ Pregravid BMI (kg/m²) } & Group A & $21.40 \pm 0.34$ & $21.88 \pm 1.07$ & $21.52 \pm 0.42$ & $21.35 \pm 0.47$ \\
\hline & Group B & $21.24 \pm 0.40$ & $23.56 \pm 1.52$ & $21.53 \pm 0.46$ & $20.82 \pm 0.71$ \\
\hline \multirow[t]{2}{*}{ Sum of fetal birth weight (g) } & Group A & $4988.73 \pm 75.80^{*}$ & $4869.33 \pm 172.2$ & $4968.57 \pm 87.99$ & $4981.28 \pm 106.84$ \\
\hline \multirow{2}{*}{\multicolumn{6}{|c|}{ Maternal BMI (kg/m²) }} \\
\hline & & & & & \\
\hline \multirow[t]{2}{*}{ Interval-I } & Group A & $0.52 \pm 0.11^{*}$ & $0.59 \pm 0.17$ & $0.56 \pm 0.13^{*}$ & $0.46 \pm 0.13^{*}$ \\
\hline & Group B & $-2.23 \pm 1.38$ & $0.73 \pm 0.81$ & $-1.59 \pm 1.42$ & $-3.62 \pm 3.25$ \\
\hline \multirow[t]{2}{*}{ Interval-II } & Group A & $3.06 \pm 0.12^{*}$ & $2.42 \pm 0.17^{*}$ & $2.87 \pm 0.12^{*}$ & $3.22 \pm 0.26$ \\
\hline & Group B & $5.10 \pm 1.32$ & $1.37 \pm 0.17$ & $5.10 \pm 1.44$ & $4.28 \pm 2.76$ \\
\hline \multirow[t]{2}{*}{ Interval-III } & Group A & $3.31 \pm 0.17^{*}$ & $3.16 \pm 0.44$ & $3.22 \pm 0.17^{*}$ & $3.46 \pm 0.35$ \\
\hline & Group B & $2.15 \pm 0.68$ & $2.30 \pm 0.75$ & $2.01 \pm 0.38$ & $2.63 \pm 2.53$ \\
\hline \multicolumn{6}{|l|}{ Twin weight discordance (\%) } \\
\hline \multirow[t]{2}{*}{ Interval-I } & Group A & $7.60 \pm 0.71^{*}$ & $12.63 \pm 1.45$ & $8.62 \pm 0.81$ & $7.49 \pm 1.15^{*}$ \\
\hline & Group B & $11.26 \pm 1.29$ & $16.36 \pm 5.80$ & $10.69 \pm 1.35$ & $14.16 \pm 2.96$ \\
\hline \multirow[t]{2}{*}{ Interval-II } & Group A & $7.80 \pm 0.58^{*}$ & $7.77 \pm 1.70$ & $7.64 \pm 0.66^{*}$ & $8.17 \pm 1.01^{*}$ \\
\hline & Group B & $13.49 \pm 1.43$ & $7.70 \pm 4.73$ & $12.78 \pm 1.66$ & $14.48 \pm 2.48$ \\
\hline \multirow[t]{2}{*}{ Interval-III } & Group A & $9.0 \pm 0.61^{*}$ & $9.47 \pm 1.28^{*}$ & $9.00 \pm 0.67^{*}$ & $9.22 \pm 0.95^{*}$ \\
\hline & Group B & $32.95 \pm 1.22$ & $32.27 \pm 2.15$ & $32.36 \pm 1.25$ & $34.71 \pm 2.84$ \\
\hline
\end{tabular}

BMI (Body Mass Index); Mean \pm SEM, * $p<0.05$ between Group A and Group B. 
gestational period are depicted in Fig. 1B. The change in mean twin weight discordance for Group A at each interval did not show any significant differences $(\alpha=0.05): 8.29 \%$ at Interval-I, 7.79\% at Interval-II, and $9.07 \%$ at Interval-III. However, Group B showed a significant increase from Interval-II to Interval-III $(\alpha=0.05)$, while there was only slight increase from Interval-I to Interval-II: $11.54 \%$ at Interval-I, $13.19 \%$ at Interval-II, and $32.92 \%$ at Interval-III. Therefore for Group B, the difference in twin weight discordance between groups was marginal at early gestational periods, but became much more significant at later periods.

Table 2 shows the mean values of maternal characteristics with respect to chorionicity and fetal gender, two factors which are known to have a significant effect on twin weight discordance. Women with monochorionic twin pregnancies were younger $(p=0.021)$ and had lower parity $(p=0.005)$ than women with dichorionic twin pregnancies. In twin pregnancies with at least one male infant, there was no significant difference between Groups A and B with regard to age, parity, pregnancy duration, and pregravid BMI. Pregnancies with both female infants also showed no significant difference between the two groups with regard to the same maternal factors except for the factor of age.

Table 3 shows the two-way ANOVA test results. For this test, the first factor was the twin birth weight discordance with two levels (Groups A and B) and the second factor was gestational interval with three levels (Interval-I, Interval-II and Interval-III). The dependent variables were maternal BMI changes and twin weight discordance at the three gestational intervals. Groups A and B had clearly different twin weight discordance at each interval $(p=0.000)$. However, if gestational intervals were not considered, no significant difference in BMI changes were observed between the two groups $(p=0.223)$. When the gestational intervals were considered, both twin weight discordance and maternal BMI change were significantly different between the two groups $(p=0.000)$. Furthermore, when twin birth weight discordance and gestational intervals were considered simultaneously, both factors had a significant effect on maternal BMl changes and twin weight discordance $(p=0.000)$.

Twin pregnancies with less than $25 \%$ discordance at delivery showed a pattern of constant maternal weight gain and no significant change of twin weight discordance throughout the gestational periods. On the contrary, in the twin pregnancies with more than $25 \%$ discordance at delivery, maternal weight change showed serious fluctuation throughout the gestational periods. This weight fluctuation might cause a remarkable increase in twin weight discordance during the third gestational interval. These observations suggest a relationship between maternal BMI change and twin weight discordance, although the correlation analysis did not show any statistical significance due to wide variances in maternal BMl changes and in twin weight discordances (data not shown). The apparent combined effect of twin birth weight discordance and gestational intervals on changes in the maternal BMI as well as twin weight discordance indicates that twin birth weight discordance can discriminate different patterns of maternal weight change at each gestational interval. This implies that the pattern of maternal BMI change might have some effect on twin birth weight discordance because maternal BMI change is a causal variable instead of an effect variable. In conclusion, the results suggest that in twin pregnancies constant maternal weight gain throughout gestation is important for maintaining a twin weight discordance of less than $25 \%$.

\section{Discussion}

With the advanced and prevalent uses of ultrasonography, fetal biometrics during pregnancy have become more accessible, leading to the successful estimation of twin weight discordance. In this study, a retrospective chart review was performed on 147 twin pregnancies that satisfied various inclusion criteria. In order to focus on the patterns of variation in maternal weight gain and fetal weight discordance, eligible twin pairs were divided into two groups depending on birth weight discordance. These two groups did not show significant differences for any other factors. The patterns of the mean maternal weight change in twin pregnancies agreed with previous reports, although the actual gestational intervals were slightly different from this study $[13,14,18]$.

The present study has found that the weight discordance of twins at an early stage remained unchanged as long as maternal weight constantly increased throughout pregnancy. However, we observed that pregnancies with higher discordances had slight decreases in maternal weight during

Table 3 2-Way ANOVA test: the differences of maternal BMI change and twin weight discordance between Group A and Group B at each gestational interval

\begin{tabular}{|c|c|c|c|c|c|}
\hline \multirow[t]{2}{*}{ Variables } & & \multicolumn{2}{|c|}{ Maternal BMI } & \multicolumn{2}{|c|}{ Twin weight discordance } \\
\hline & & Group A & Group B & Group A & Group B \\
\hline $\begin{array}{l}\text { Interval-I } \\
\text { Interval-II } \\
\text { Interval-III } \\
\end{array}$ & & $\begin{array}{l}0.53 \pm 0.10 \\
2.97 \pm 0.11 \\
3.29 \pm 0.16 \\
\end{array}$ & $\begin{array}{r}-2.01 \pm 1.32 \\
4.91 \pm 1.26 \\
2.16 \pm 0.64 \\
\end{array}$ & $\begin{array}{l}8.29 \pm 0.67 \\
7.79 \pm 0.55 \\
9.07 \pm 0.55 \\
\end{array}$ & $\begin{array}{l}11.54 \pm 1.25 \\
13.19 \pm 1.38 \\
32.92 \pm 1.16 \\
\end{array}$ \\
\hline $\begin{array}{l}p \text {-value for main and } \\
\text { combined effect }\end{array}$ & $\begin{array}{l}\text { Twin birth discordance } \\
\text { Gestational intervals } \\
\text { Twin birth discordance and } \\
\text { gestational intervals }\end{array}$ & $\begin{array}{l}0.223 \\
0.000 \\
0.000\end{array}$ & & $\begin{array}{l}0.000 \\
0.000 \\
0.000\end{array}$ & \\
\hline
\end{tabular}

BMI (Body Mass Index); Mean \pm SEM. 
early-pregnancy and significant weight gain during midpregnancy. An abrupt increase in maternal weight at the midpregnancy stage might aggravate twin weight discordance by limiting the maternal weight that is gained in latepregnancy. These dissimilar patterns of maternal BMI changes and twin weight discordances between low and high birth-weight-discordant pregnancies have also been found in other factors like chorionicity and discordant gender $[19,20]$.

Though twin weight discordance occasionally accompanies adverse perinatal outcomes, it is not always an indication of abnormal fetal growth. In recent studies, inter-twin birth weight discordance was reported to be a normal growth variation $[5,9,21]$.

This study suggests that constant maternal weight gain throughout the gestational period in twin pregnancy is important for keeping twin birth weight discordance low. During antenatal cares, infant nutrition can be controlled by managing an appropriate maternal weight. Modern advanced technologies have made it much easier to examine fetal developmental status. Therefore, it is strongly recommended that proper nutritional intervention be provided from an early gestational stage and that an inter-twin growth evaluation be performed frequently in order to minimize adverse outcomes by high weight discordance in twin babies.

The limitations of this study include its retrospective nature, small-sized study population $(n=147)$, exclusion of other fetal biometric data from ultrasonography, and low frequency of examination. Despite these limitations, our results suggest that an appropriate and constant maternal weight increase during twin pregnancy can lead to lower twin weight discordance throughout the pregnancy and maternal weight gain can be used as an indicator for abnormal twin weight discordance.

\section{References}

[1] Blondel BKM. Trends in the occurrence, determinants, and consequences of multiple births. Semin Perinatol 2002;26: 239-49.

[2] Spellacy WN, Handler A, Ferre CD. A case-control study of 1253 twin pregnancies from a 1982-1987 perinatal data base. Obstet Gynecol 1990;75:168-71.

[3] Blickstein I, Keith LG. Neonatal mortality rates among growthdiscordant twins, classified according to the birth weight of the smaller twin. Am J Obstet Gynecol 2004;190:170-4.

[4] Branum AM, Schoendorf KC. The effect of birth weight discordance on twin neonatal mortality. Obstet Gynecol 2003;101:570-4.
[5] Blickstein I, Goldman RD, Mazkereth R. Adaptive growth restriction as a pattern of birth weight discordance in twin gestations. Obstet Gynecol 2000;96:986-90.

[6] King JC. Determinants of maternal zinc status during pregnancy. Am J Clin Nutr 2000;71:1334S-43S.

[7] Ramakrishnan U, Neufeld L. Recent advances in nutrition and intrauterine growth. In: Martorell R, Haschke F, editors. Nestle Nutrition Workshop Series, Pediatric Program. Phliadelphia: Lippincott Williams and Wiklins; 2001. p. 97-122.

[8] Scholl TO, Reilly T. Anemia, iron and pregnancy outcome. J Nutr 2000;130:443S-7S.

[9] Blickstein I. Normal and abnormal growth of multiples. Semin Neonatol 2002;7:177-85.

[10] Li R, Haas JD, Habicht J. Timing of the influence of maternal nutritional status during pregnancy on fetal growth. Am J Human Biol 1998;10:529-39.

[11] Luke B, Newman RB. Maternal nutrition. In: Luke B, Newman RB, editors. Multifetal Pregnancy: Care of the Pregnant Patient. Philadelphia, PA/Baltimore, MD: Lippincott/Williams and Wilkins; 2000. p. 192-219.

[12] Luke B, Nugent C, van de Ven C, Martin D, O'Sullivan MJ, Eardley $S$, et al. The association between maternal factors and perinatal outcomes in triplet pregnancies. Am J Obstet Gynecol 2002; $187: 752-7$.

[13] Luke B, Gillespie B, Min SJ, Avni M, Witter FR, O'Sullivan MJ. Critical periods of maternal weight gain: effect on twin birth weight. Am J Obstet Gynecol 1997;177:1055-62.

[14] Luke B, Min SJ, Gillespie B, Avni M, Witter FR, Newman RB, et al. The importance of early weight gain in the intrauterine growth and birth weight of twins. Am J Obstet Gynecol 1998;179: 1155-61.

[15] Luke B, Bryan E, Sweetland C, Leurgans S, Keith L. Prenatal weight gain and the birthweight of triplets. Acta Genet Med Gemellol (Roma) 1995;44:93-101.

[16] Blickstein I, Goldman RD, Smith-Levitin M, Greenberg M, Sherman D, Rydhstroem $\mathrm{H}$. The relation between inter-twin birth weight discordance and total twin birth weight. Obstet Gynecol 1999;93:113-6.

[17] Hadlock FP, Harrist RB, Carpenter RJ. Sonographic estimation of fetal weight. The value of femur length in addition to head and abdomen measurements. Radiology 1984;150:535-40.

[18] Brown JE, Carlson M. Nutrition and multifetal pregnancy. J Am Diet Assoc 2000;100:343-8.

[19] Tan H, Wen SW, Fung Kee Fung, Walker M, Demissie K. The distribution of intra-twin birth weight discordance and its association with total twin birth weight, gestational age, and neonatal mortality. Eur J Obstet Gynecol Reprod Biol 2005;121: 27-33.

[20] Eberle AM, Levesque D, Vintzileos AM, Egan JF, Tsapanos V, Salafia CM. Placental pathology in discordant twins. Am J Obstet Gynecol 1993;169:931-5.

[21] Hickey CA, Cliver SP, McNeal SF, Hoffman HJ, Goldenberg RL. Prenatal weight gain patterns and birth weight among nonobese black and white women. Obstet Gynecol 1996;88: 490-6. 